\title{
Superoxide-Mediated Extracellular Biosynthesis of Silver Nanoparticles by the Fungus Fusarium oxysporum
}

\author{
Yongguang Yin, ${ }^{\dagger, \dagger}$ Xiaoya Yang, ${ }^{\dagger} \S$ Ligang Hu, ${ }^{\dagger}$ Zhiqiang Tan $^{\dagger}$ Lixia Zhao, $^{\dagger}$ Zhen Zhang, ${ }^{\S}$ Jingfu Liu, $^{*}, \dagger$ \\ and Guibin Jiang ${ }^{\dagger}$ \\ ${ }^{\dagger}$ State Key Laboratory of Environmental Chemistry and Ecotoxicology, Research Center for Eco-Environmental Sciences, Chinese \\ Academy of Sciences, Beijing 100085, China \\ ${ }^{\ddagger}$ Institute of Environment and Health, Jianghan University, Wuhan 430056, China \\ ${ }^{\S}$ School of the Environment, Jiangsu University, Zhenjiang 212013, China
}

Supporting Information

ABSTRACT: The biosynthesis of silver nanoparticles (AgNPs) by microorganisms has become a hot topic in recent years, although its mechanism is still not well understood. Here we report the extracellular biosynthesis of AgNPs by the fungus Fusarium oxysporum through a superoxide-dependent mechanism. Reduction of $\mathrm{Ag}^{+}$to AgNPs in the extracellular region of $F$. oxysporum was verified by transmission electron microscopy, while the superoxide produced extracellularly by F. oxysporum was evidenced by chemiluminescence. We further demonstrated that the biosynthesis of AgNPs was inhibited by a superoxide scavenger or the inhibitor of NADH oxidases, and the addition of $\mathrm{NADH}$ significantly improved the formation of AgNPs. These results demonstrated that, for the first time, the fungus F. oxysporum can mediate the synthesis of AgNPs through the enzymatic generation of extracellular superoxide, which is helpful in understanding the biosynthesis of AgNPs and the biomineralization and transformation of silver and other metals or metalloids.

\section{INTRODUCTION}

Because of the wide application of silver nanoparticles (AgNPs), ${ }^{1-4}$ there is an ever-growing need to develop environmentally friendly processes for their synthesis. As inspired by the bioreduction of silver ion $\left(\mathrm{Ag}^{+}\right)$by Pseudomonas stutzeri, ${ }^{5}$ the biosynthesis of AgNPs with microorganisms has become a hot topic, which was suggested as a green approach to synthesizing AgNPs. ${ }^{6}$ These AgNPs are usually localized extracellularly, ${ }^{6}$ which would simplify the downstream processing. ${ }^{7,8}$ Although the biosynthesis of AgNPs has been demonstrated with a variety of bacteria, fungi, and actinomycetes, ${ }^{6}$ the mechanism of this process is yet to be elucidated, which will be helpful for the enhancement of AgNP synthesis ${ }^{9}$ as well as our understanding of the biomineralization of silver and the formation of naturally occurring AgNPs. ${ }^{10}$ Several studies suggested that nitrate reductase (NR) was involved in this bioreduction process. ${ }^{11-14}$ It was observed that the fungus Fusarium oxysporum can mediate AgNP synthesis, ${ }^{15}$ and NR purified from F. oxysporum can reduce $\mathrm{Ag}^{+}$into AgNPs. ${ }^{9}$ In addition, NR inhibitor piperitone can partially inhibit the biological reduction of $\mathrm{Ag}^{+}$to AgNPs by enterobacteria. ${ }^{16}$ Infrared spectrometry and ${ }^{13} \mathrm{C}$ nuclear magnetic resonance suggested that aldehyde groups of extracellular polysaccharides may also play a crucial role in the reduction. ${ }^{17,18}$ These results suggested that multimechanisms may present for this bioreduction. However, the pathway and electron donor involved in this process are still not well understood.

Recently, it has been demonstrated that bacteria and fungi can produce superoxide, ${ }^{19,20}$ which can further mediate the oxidation of $\mathrm{Mn}(\mathrm{II})^{20,21}$ and $\mathrm{I}^{-22}$ and the reduction of $\mathrm{Fe}(\mathrm{III}){ }^{23,24}$ As demonstrated previously, superoxide produced from $\mathrm{KO}_{2}{ }^{25,26}$ or photoirradiated natural organic matter ${ }^{27}$ can also reduce $\mathrm{Ag}^{+}$into AgNPs. Therefore, it is reasonable that superoxide bioproduced by microorganisms could reduce $\mathrm{Ag}^{+}$ into AgNPs.

The main objective of this study was to probe the role of bioproduced superoxide in the microorganism-mediated biosynthesis of AgNPs, by using the fungus F. oxysporum as a model. We hypothesized F. oxysporum produces extracellular superoxide, which can subsequently reduce $\mathrm{Ag}^{+}$into extracellular AgNPs. To test this hypothesis, the extracellular formation of superoxide and AgNPs was demonstrated by continuous flow chemiluminescence (CL) and transmission electron microscopy (TEM), respectively. Then the role of superoxide in the biosynthesis of AgNPs was symmetrically

Received: February 23, 2016

Revised: $\quad$ March 21, 2016

Accepted: March 22, 2016

Published: March 22, 2016 

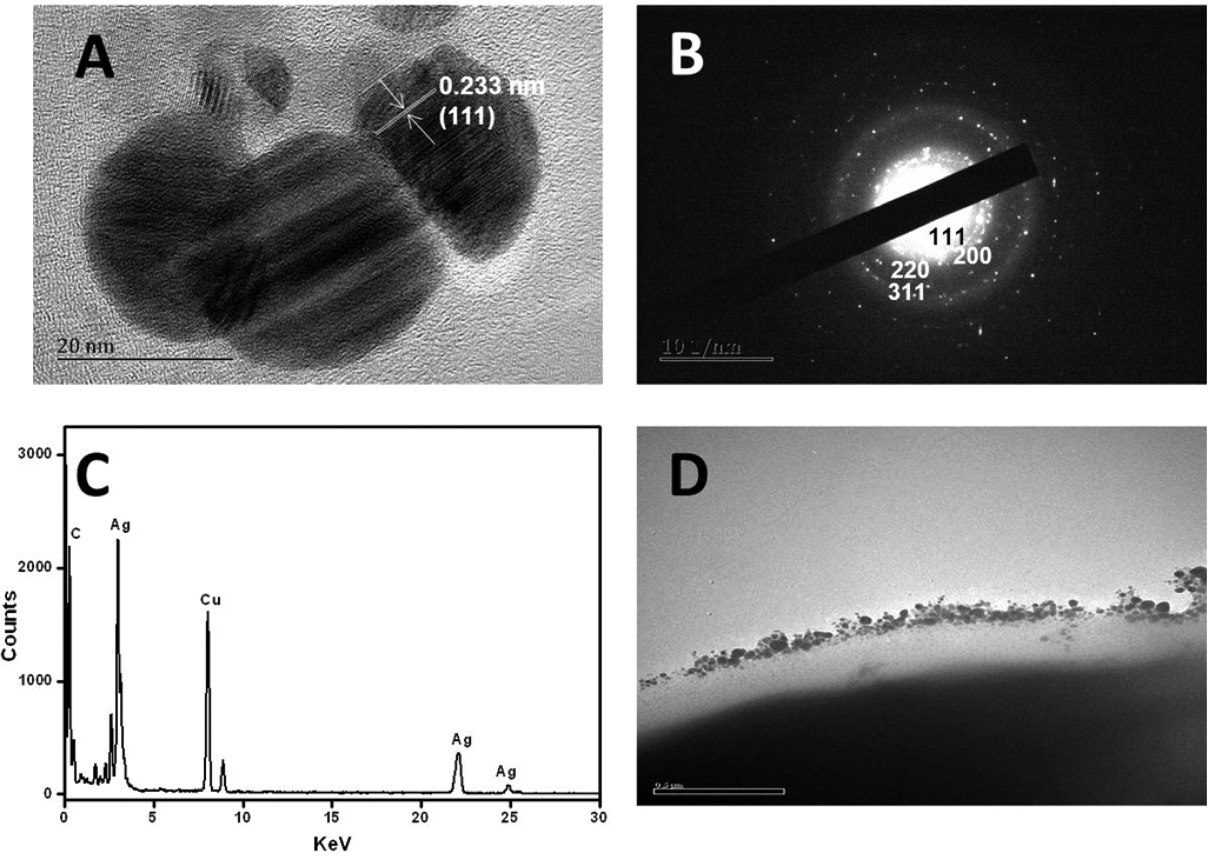

Figure 1. Extracellular synthesis of AgNPs by fungus F. oxysporum as demonstrated by (A) high-resolution TEM, (B) SAED, (C) EDS, and (D) TEM. The scale bars in panels $A$ and $D$ are $20 \mathrm{~nm}$ and $0.5 \mu \mathrm{m}$, respectively.

examined by using heat sterilization and the addition of a superoxide scavenger, reduced nicotinamide adenine dinucleotide $(\mathrm{NADH})$, or a $\mathrm{NADH}$ enzyme inhibitor.

\section{MATERIALS AND METHODS}

Materials. F. oxysporum, separated from soybean root soil, was purchased from China General Microbiological Culture Collection Center (CGMCC, catalog no. 3.6787). Potato dextrose broth (PDB) and potato dextrose agar (PDA) were from Aobox Biotechnology (Beijing, China). Analytical grade $\mathrm{AgNO}_{3}$, glucose, $\mathrm{Zn}\left(\mathrm{NO}_{3}\right)_{2}$, and $\mathrm{Cu}\left(\mathrm{NO}_{3}\right)_{2}$ were purchased from Sinopharm Chemicals (Shanghai, China). Superoxide dismutase (SOD) from bovine erythrocytes, diphenyleneiodonium chloride (DPI), NADH, and $\mathrm{NAD}^{+}$were from SigmaAldrich (St. Louis, MO). Other chemicals were from Beijing Chemicals (Beijing, China). Ultrapure water $(18.3 \mathrm{M} \Omega$ ) from a Milli-Q gradient system (Millipore, Bedford, MA) was used throughout the experiments.

Cell Culture of $F$. oxysporum. PDA medium is more favorable for the growth of $F$. oxysporum, while the PDB liquid medium can facilitate the separation of $F$. oxysporum from the matrix. Thus, first the frozen-dried F. oxysporum was suspended in $0.3-0.5 \mathrm{~mL}$ of PDB medium and transferred onto PDA slant culture medium to active the mycelia at $25{ }^{\circ} \mathrm{C}$. Then the $F$. oxysporum was inoculated into $100 \mathrm{~mL}$ of PDB medium and cultured at $25{ }^{\circ} \mathrm{C}$ while being shaken at $180 \mathrm{rpm}$ for 4 days.

Treatment of $F$. oxysporum and the Biosynthesis of AgNPs. To prevent the interference from the culture medium for biosynthesis of AgNPs, F. oxysporum in its fast-growing period was first washed three times with sterilized water via centrifugation $\left(2000 \mathrm{~g}\right.$ for $20 \mathrm{~min}$ at $10{ }^{\circ} \mathrm{C}$ ) and then diluted with sterilized water to a final volume of $20 \mathrm{~mL}$. The obtained F. oxysporum solution was then filtered through sterilized monolayered gauze (pore size of $1 \mathrm{~mm} \times 1 \mathrm{~mm}$ ) for further experiments.

Into a sterile glass tube $(15 \mathrm{~mm} \times 100 \mathrm{~mm})$ were sequentially added $5 \mathrm{~mL}$ of a filtered $F$. oxysporum solution,
$2 \%(\mathrm{~m} / \mathrm{v})$ glucose (as an energy source to maintain the growth of fugus), and $\mathrm{AgNO}_{3}\left(1 \mathrm{mmol} \mathrm{L}{ }^{-1}\right)$, and the tube was sealed with a cotton plug. The glass tube was kept at $25{ }^{\circ} \mathrm{C}$ while being shaken at $150 \mathrm{rpm}$. The solution sampled at different times was filtered through $0.2 \mu \mathrm{m}$ glass fiber filter for further characterization.

To probe the possible role of superoxide and oxidoreductase in the biosynthesis of AgNPs, the superoxide scavenger [SOD and $\left.\mathrm{Cu}\left(\mathrm{NO}_{3}\right)_{2}\right]\left[\mathrm{Zn}\left(\mathrm{NO}_{3}\right)_{2}\right.$ as a control], $\mathrm{NADH}, \mathrm{NAD}^{+}$, and oxidoreductase inhibitor (DPI) were also added to investigate their effects on the biosynthesis of AgNPs.

Characterization of AgNPs. The UV-visible (vis) spectra were recorded by using a UV-vis-NIR spectrometer (UV3600, Shimadzu). TEM, coupled with an energy dispersive spectrometer (EDS) and selected area electron diffraction (SAED), was conducted with a H-7500 (Hitachi) or JEM 2100F (JEOL) instrument.

Detection of Superoxide by CL. A continuous flow CL apparatus $^{28}$ was used for online detection of superoxide from $F$. oxysporum. The apparatus includes a CL analyzer (Institute of Biophysics, Beijing, China) and two peristaltic pumps (Longer Precision Pump Co., Hebei, China). It should be noted that the photoreactor in a previous study ${ }^{28}$ was omitted in this study. Methyl cypridina luciferin analogue (MCLA, $0.1 \mathrm{mmol} \mathrm{L}^{-1}, \mathrm{pH}$ 11.6) was mixed with $F$. oxysporum through Tygon pump tubing (inside diameter of $1 \mathrm{~mm}$ ), and the CL intensity is measured with a photomultiplier tube at the spiral detection cell in the CL analyzer.

\section{RESULTS AND DISCUSSION}

Extracellular Synthesis of AgNPs by F. oxysporum. After incubation of $\mathrm{AgNO}_{3}$ with $F$. oxysporum for $12 \mathrm{~h}$, the formation of AgNPs was demonstrated comprehensively by TEM, SAED, and EDS (Figure 1). Spherical particles with an average diameter of $20.7 \mathrm{~nm}$ (Figure S1) were observed. The lattice planes observed in the TEM image (Figure 1A) and SAED patterns (Figure 1B) can be indexed to face-centered 
cubic silver metal. EDS (Figure 1C) further confirmed these nanoparticles are silver. Other signals of $\mathrm{C}$ and $\mathrm{Cu}$ are from the carbon-coated copper grid. The TEM image in Figure 1D revealed that these AgNPs are located extracellularly, which is consistent with the finding of Ahmad et al. ${ }^{15}$ These combined results demonstrated that the live fungus $F$. oxysporum can extracellularly synthesize AgNPs.

The evolution of AgNPs with incubation time was further probed by UV-vis spectrometry (Figure S2). The UV-vis spectrum of the blank (2\% glucose and $\mathrm{AgNO}_{3}$ incubated at 25 ${ }^{\circ} \mathrm{C}$ for $48 \mathrm{~h}$ ) did not show any surface plasmon resonance (SPR) absorption from AgNPs, demonstrating that glucose in the matrix should not produce any artifact of AgNPs during the incubation procedure. Figure S2 indicates the SPR intensity from AgNPs at $\sim 450 \mathrm{~nm}$ increased with incubation time, suggesting the increased AgNPs concentration accordingly. ${ }^{27}$

Production of Superoxide by $F$. oxysporum. It was reported that superoxide can be produced by bacteria and fungi. ${ }^{19-21,23,24}$ Here, for the first time, we demonstrated the production of superoxide by F. oxysporum by using continuous flow CL (Figure 2). No CL signal was observed when only F.

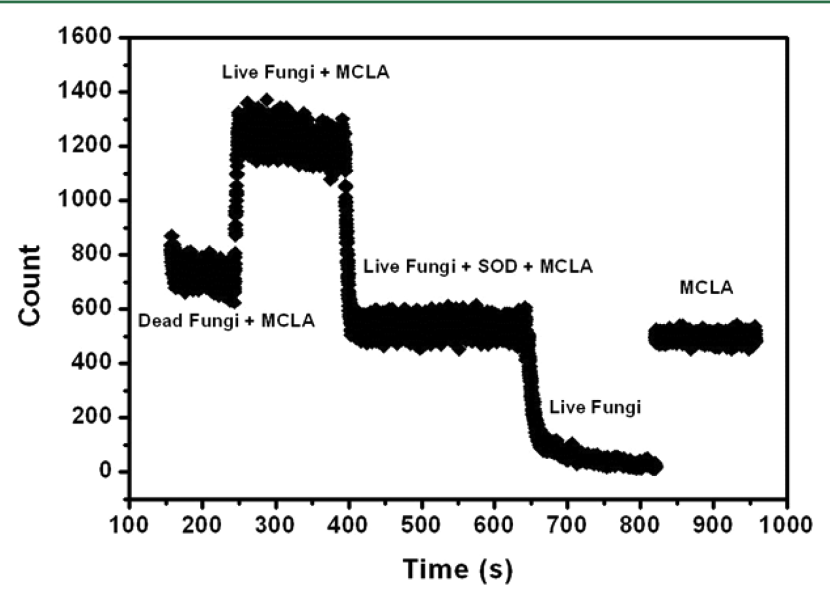

Figure 2. Online detection of superoxide produced by the fungus $F$. oxysporum by using continuous flow chemiluminescence. The concentration of SOD is 600 units $\mathrm{mL}^{-1}$.

oxysporum was present (in the absence of CL reagent, MCLA), indicating the F. oxysporum would not interfere with the CL determination. In the absence of $F$. oxysporum, MCLA can produce a weak CL signal; however, a continuous enhanced CL signal was observed when F. oxysporum was mixed with MCLA, suggesting a continuous production of superoxide by fungi at an approximately constant rate. However, the magnitude of the $\mathrm{CL}$ signal decreased significantly in the presence of a specific superoxide scavenger, SOD, which further confirmed that the CL signal was from superoxide. In addition, after the fungus was heat-deactivated, the magnitude of the CL signal decreased significantly, suggesting the superoxide was produced by live $F$. oxysporum. Superoxide, as a charged radical species, is unlikely to be able to diffuse through the cell membrane, ${ }^{29}$ and exogenous macromolecular SOD also cannot enter the cell from the extracellular space because of the molecular-sieving function of the cell wall. ${ }^{21,30}$ Therefore, these results clearly demonstrated that the live fungus $F$. oxysporum can produce superoxide extracellularly.

Superoxide-Mediated Extracellular Biosynthesis of Silver Nanoparticles. Superoxide Scavenger. $\mathrm{Cu}^{2+}$ is an effective and rapid superoxide scavenger, while chemically similar $\mathrm{Zn}^{2+}$ cannot catalyze the dismutation of superoxide. $^{20,21,31}$ The effect of $\mathrm{Cu}^{2+}$ (as a superoxide scavenger) and $\mathrm{Zn}^{2+}$ (as a control) on the formation of AgNPs by $\mathrm{F}$. oxysporum was therefore investigated (Figure $3 \mathrm{~A}$ ). The addition of $\mathrm{Cu}^{2+}$ can induce a concentration-dependent inhibition of AgNP formation, suggesting a critical role of superoxide as the reductant of $\mathrm{Ag}^{+}$. However, addition of $\mathrm{Zn}^{2+}$ can only slightly red-shift the UV-vis spectrum. This red-shift was also observed for AgNPs in the presence of $\mathrm{Cu}^{2+}$, which should be ascribed to the divalent metal ion-induced aggregation and fusion of AgNPs. ${ }^{32,33}$

Then, SOD, a specific superoxide scavenger, ${ }^{34,35}$ was added to the growing cultures to further validate the role of superoxide in AgNP formation. Figure 3B shows that SOD can partially abolish the formation of AgNPs by F. oxysporum, demonstrating the critical role of superoxide in the reduction of silver. It should also be noted that at 600 units $\mathrm{mL}^{-1} \mathrm{SOD}$, the formation of AgNPs can still be observed. As Figure 2 demonstrates that SOD at this concentration can scavenge the fungally produced superoxide, therefore, other possible reductive processes besides superoxide should exist.

It should be also noted that in panels A and B of Figure 3, the formed AgNPs in the absence of $\mathrm{Cu}^{2+}$ or SOD showed slightly different peak shapes, although the culture of fungus and biosynthesis of AgNPs are performed under the same conditions but in different batches. The different peak shape of spectra indicated the different sizes or aggregation states of AgNPs, ${ }^{33}$ which may be associated with the experimental batchdependent composition and concentration of extracellular polymeric substances that play an important role in stabilizing AgNPs. ${ }^{36}$

Activity of Enzymes Responsible for Superoxide Production. A variety of oxidoreductases can produce superoxide by engaging one-electron transfer from substrate to $\mathrm{O}_{2}$, including $\mathrm{NAD}(\mathrm{P}) \mathrm{H}$ oxidases, ${ }^{37,38}$ multicopper oxidases, ${ }^{39}$ and $\mathrm{NR}^{40}$ Thus, the role of the primary enzymes, $\mathrm{NAD}(\mathrm{P}) \mathrm{H}$ oxidases, responsible for superoxide production was investigated in the formation of AgNPs by F. oxysporum.

DPI, an inhibitor of transmembrane oxidoreductases and other $\mathrm{NAD}(\mathrm{P}) \mathrm{H}$ binding enzymes, ${ }^{41}$ results in the partial inhibition of AgNP formation at 12 and $24 \mathrm{~h}$ (Figure 3C,D). In addition, a concentration-dependent inhibition of DPI on AgNPs was observed, which further supports the possibility that superoxide-mediated AgNP formation is associated with the activity of $\mathrm{NAD}(\mathrm{P}) \mathrm{H}$ oxidase enzymes.

$\mathrm{NAD}(\mathrm{P}) \mathrm{H}$ oxidases, located within the plasma membrane, can utilize cytosolic $\mathrm{NADH}$ as the substrate to reduce $\mathrm{O}_{2}$ to extracellular superoxide. ${ }^{19}$ Therefore, the role of the oxidase substrate, i.e., $\mathrm{NADH}$, was studied in AgNP formation. As shown in Figure S3, NADH significantly enhanced the formation of AgNPs by F. oxysporum. However, the addition of the oxidized form $\mathrm{NAD}^{+}$did not increase the level of formation of AgNPs. In addition, compared with that of NADH spiking, the simultaneous addition of $\mathrm{NADH}$ and $\mathrm{SOD}$ significantly inhibits the formation of AgNPs, suggesting the $\mathrm{NADH}$-enhanced enzymatic superoxide production and the subsequent reductive formation of AgNPs by superoxide.

Live and Heat-Deactivated F. oxysporum. As demonstrated above, a superoxide scavenger can only partially inhibit the production of AgNPs by F. oxysporum, indicating the presence of another AgNP synthesis pathway besides superoxide. We then compared the heat-deactivated and live $F$. 

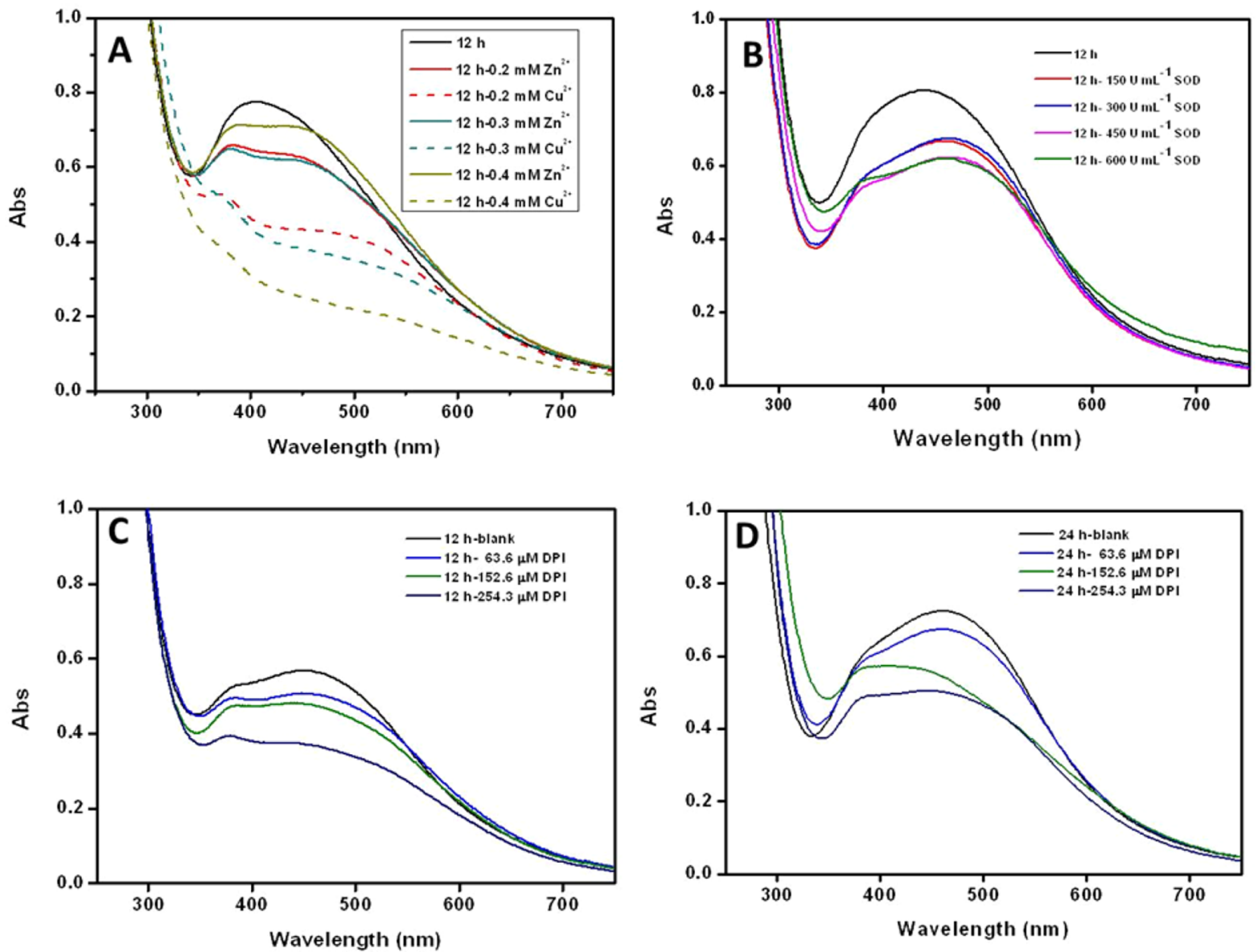

Figure 3. UV-vis absorption spectrum of AgNPs formed by F. oxysporum in the presence of (A) $\mathrm{Cu}^{2+}$ or $\mathrm{Zn}^{2+}$, (B) SOD, and (C and D) DPI after incubation for 12 or $24 \mathrm{~h}$.

oxysporum for their AgNP synthesis capability. As shown in Figure S4, although the heat deactivation of F. oxysporum significantly decreased the level of AgNP formation, the SPR absorption suggested there is still AgNP formation even in the presence of heat-deactivated F. oxysporum. As only live F. oxysporum can produce superoxide (Figure 2), the synthesis of AgNPs by heat-deactivated F. oxysporum indicated that other AgNP formation processes besides superoxide may also present for F. oxysporum. The formation of AgNPs by dead F. oxysporum could possibly be ascribed to the reductive aldehyde groups of extracellular polysaccharides. ${ }^{18}$ Figure S4 also shows that the difference in AgNP synthesis capability of dead and live F. oxysporum decreases with incubation time, possibly due to the toxicity of $\mathrm{Ag}^{+}$and thus the inhibition of cell viability and reproduction to $F$. oxysporum. ${ }^{42}$

It should be noted that several studies also suggested that NR plays a crucial role in AgNP biosynthesis, ${ }^{9,11-14}$ which is not contradictory with our proposed superoxide pathway. As NR from various sources can also reduce $\mathrm{O}_{2}$ to superoxide, ${ }^{40,43-45}$ it is reasonable that the previously proposed NR pathway also involved superoxide as a reductant.

Environmental Implications. Living bacteria, fungi, algae, and plant species can reduce $\mathrm{Ag}^{+}$into $\mathrm{AgNPs}^{6}$ and potentially serve as "nano-factories" for AgNP synthesis. ${ }^{46,47}$ Here we discovered superoxide plays a crucial role in the extracellular synthesis of AgNPs by the fungus F. oxysporum. As superoxide is widely produced in bacteria, ${ }^{19}$ fungi, ${ }^{20}$ algae, ${ }^{48}$ and plants, ${ }^{49}$ this study is helpful for understanding the mechanism of AgNP biosynthesis, which will have great implications for the enhancement of AgNP synthesis in the future. In addition, this study also improves our understanding of biomineralization of silver and the source of naturally occurring AgNPs. As the antibacterial activities of AgNPs are much lower than that of $\mathrm{Ag}^{+},{ }^{50}$ this bioreduction is also a possible natural antidote to mitigate the toxicity of silver to organisms. Considering the key roles of superoxide in the redox cycles of $\mathrm{Fe}^{23,51} \mathrm{Mn},{ }^{20,21}$ $\mathrm{Cu}^{32,52,53} \mathrm{Cr},{ }^{54,55} \mathrm{As},{ }^{56,57}$ and $\mathrm{I}^{22}$ it is expected that the superoxide-produced organisms should also have great impacts on the biogeochemical cycles of these elements.

\section{ASSOCIATED CONTENT}

\section{Supporting Information}

The Supporting Information is available free of charge on the ACS Publications website at DOI: 10.1021/acs.estlett.6b00066.

TEM image and size distribution of AgNPs and and the UV-vis spectrum of AgNPs under different conditions (PDF)

\section{AUTHOR INFORMATION}

\section{Corresponding Author}

*E-mail: jfliu@rcees.ac.cn. Phone: +86-10-62849192.

\section{Notes}

The authors declare no competing financial interest. 


\section{ACKNOWLEDGMENTS}

This work was supported by the National Natural Science Foundation of China (21522705 and 21337004) and the Strategic Priority Research Program of the Chinese Academy of Sciences (XDB14020101).

\section{REFERENCES}

(1) Kamat, P. V. Photophysical, Photochemical and Photocatalytic Aspects of Metal Nanoparticles. J. Phys. Chem. B 2002, 106, 77297744.

(2) Haes, A. J.; Van Duyne, R. P. A Nanoscale Optical Blosensor: Sensitivity and Selectivity of an Approach Based on the Localized Surface Plasmon Resonance Spectroscopy of Triangular Silver Nanoparticles. J. Am. Chem. Soc. 2002, 124, 10596-10604.

(3) Rai, M.; Yadav, A.; Gade, A. Silver Nanoparticles as a New Generation of Antimicrobials. Biotechnol. Adv. 2009, 27, 76-83.

(4) Sharma, V. K.; Yngard, R. A.; Lin, Y. Silver Nanoparticles: Green Synthesis and Their Antimicrobial Activities. Adv. Colloid Interface Sci. 2009, 145, 83-96.

(5) Klaus, T.; Joerger, R.; Olsson, E.; Granqvist, C. G. Silver-Based Crystalline Nanoparticles, Microbially Fabricated. Proc. Natl. Acad. Sci. U. S. A. 1999, 96, 13611-13614.

(6) Yin, Y. G.; Yu, S. J.; Yang, X. Y.; Liu, J. F.; Jiang, G. B. Source and Pathway of Silver Nanoparticles. In Silver Nanoparticles in the Environment; Springer-Verlag: Berlin, 2015.

(7) Kowshik, M.; Ashtaputre, S.; Kharrazi, S.; Vogel, W.; Urban, J.; Kulkarni, S. K.; Paknikar, K. M. Extracellular Synthesis of Silver Nanoparticles by a Silver-Tolerant Yeast Strain MKY3. Nanotechnology 2003, 14, 95-100.

(8) Bhainsa, K. C.; D’Souza, S. F. Extracellular Biosynthesis of Silver Nanoparticles Using the Fungus Aspergillus fumigatus. Colloids Surf., B 2006, 47, 160-164.

(9) Anil Kumar, S.; Abyaneh, M. K.; Gosavi, S. W.; Kulkarni, S. K.; Pasricha, R.; Ahmad, A.; Khan, M. I. Nitrate Reductase-Mediated Synthesis of Silver Nanoparticles from $\mathrm{AgNO}_{3}$. Biotechnol. Lett. 2007, 29, 439-445.

(10) Weisener, C. G.; Babechuk, M. G.; Fryer, B. J.; Maunder, C. Microbial Dissolution of Silver Jarosite: Examining Its Trace Metal Behaviour in Reduced Environments. Geomicrobiol. J. 2008, 25, 415424.

(11) Durán, N.; Marcato, P. D.; Alves, O. L.; De Souza, G. I. H.; Esposito, E. Mechanistic Aspects of Biosynthesis of Silver Nanoparticles by Several Fusarium oxysporum Strains. J. Nanobiotechnol. 2005, 3, 8 .

(12) Ingle, A.; Gade, A.; Pierrat, S.; Sonnichsen, C.; Rai, M. Mycosynthesis of Silver Nanoparticles Using the Fungus Fusarium acuminatum and Its Activity against Some Human Pathogenic Bacteria. Curr. Nanosci. 2008, 4, 141-144.

(13) Vaidyanathan, R; Gopalram, S.; Kalishwaralal, K.; Deepak, V.; Pandian, S. R. K.; Gurunathan, S. Enhanced Silver Nanoparticle Synthesis by Optimization of Nitrate Reductase Activity. Colloids Surf., B 2010, 75, 335-341.

(14) Lin, I. W. S.; Lok, C. N.; Che, C. M. Biosynthesis of Silver Nanoparticles from Silver(I) Reduction by the Periplasmic Nitrate Reductase c-Type Cytochrome Subunit NapC in a Silver-Resistant E. coli. Chem. Sci. 2014, 5, 3144-3150.

(15) Ahmad, A.; Mukherjee, P.; Senapati, S.; Mandal, D.; Khan, M. I.; Kumar, R.; Sastry, M. Extracellular Biosynthesis of Silver Nanoparticles using the Fungus Fusarium oxysporum. Colloids Surf., B 2003, 28, 313318.

(16) Shahverdi, A. R.; Minaeian, S.; Shahverdi, H. R.; Jamalifar, H.; Nohi, A. A. Rapid Synthesis of Silver Nanoparticles Using Culture Supernatants of Enterobacteria: A Novel Biological Approach. Process Biochem. 2007, 42, 919-923.

(17) Lin, Z. Y.; Zhou, C. H.; Wu, J. M.; Zhou, J. Z.; Wang, L. A Further Insight into the Mechanism of $\mathrm{Ag}^{+}$Biosorption by Lactobacillus sp Strain A09. Spectrochim. Acta, Part A 2005, 61, $1195-1200$.
(18) Kang, F. X.; Alvarez, P. J.; Zhu, D. Q. Microbial Extracellular Polymeric Substances Reduce $\mathrm{Ag}^{+}$to Silver Nanoparticles and Antagonize Bactericidal Activity. Environ. Sci. Technol. 2014, 48, 316-322.

(19) Diaz, J. M.; Hansel, C. M.; Voelker, B. M.; Mendes, C. M.; Andeer, P. F.; Zhang, T. Widespread Production of Extracellular Superoxide by Heterotrophic Bacteria. Science 2013, 340, 1223-1226. (20) Hansel, C. M.; Zeiner, C. A.; Santelli, C. M.; Webb, S. M. $\mathrm{Mn}$ (II) Oxidation by an Ascomycete Fungus is Linked to Superoxide Production during Asexual Reproduction. Proc. Natl. Acad. Sci. U. S. A. 2012, 109, 12621-12625.

(21) Learman, D. R.; Voelker, B. M.; Vazquez-Rodriguez, A. I.; Hansel, C. M. Formation of Manganese Oxides by Bacterially Generated Superoxide. Nat. Geosci. 2011, 4, 95-98.

(22) Li, H. P.; Daniel, B.; Creeley, D.; Grandbois, R.; Zhang, S. J.; Xu, C.; Ho, Y. F.; Schwehr, K. A.; Kaplan, D. I.; Santschi, P. H.; et al. Superoxide Production by a Manganese-Oxidizing Bacterium Facilitates Iodide Oxidation. Appl. Environ. Microb. 2014, 80, 2693-2699.

(23) Rose, A. L.; Salmon, T. P.; Lukondeh, T.; Neilan, B. A.; Waite, T. D. Use of Superoxide as an Electron Shuttle for Iron Acquisition by the Marine Cyanobacterium Lyngbya majuscula. Environ. Sci. Technol. 2005, 39, 3708-3715.

(24) Rose, A. L. The Influence of Extracellular Superoxide on Iron Redox Chemistry and Bioavailability to Aquatic Microorganisms. Front. Microbiol. 2012, 3, 124.

(25) Jones, A. M.; Garg, S.; He, D.; Pham, A. N.; Waite, T. D. Superoxide-Mediated Formation and Charging of Silver Nanoparticles. Environ. Sci. Technol. 2011, 45, 1428-1434.

(26) He, D.; Jones, A. M.; Garg, S.; Pham, A. N.; Waite, T. D. Silver Nanoparticle-Reactive Oxygen Species Interactions: Application of a Charging-Discharging Model. J. Phys. Chem. C 2011, 115, 5461-5468.

(27) Yin, Y. G.; Liu, J. F.; Jiang, G. B. Sunlight-Induced Reduction of Ionic $\mathrm{Ag}$ and $\mathrm{Au}$ to Metallic Nanoparticles by Dissolved Organic Matter. ACS Nano 2012, 6, 7910-7919.

(28) Wang, D. B.; Zhao, L. X.; Guo, L. H.; Zhang, H. Online Detection of Reactive Oxygen Species in Ultraviolet (UV)-Irradiated Nano- $\mathrm{TiO}_{2}$ Suspensions by Continuous Flow Chemiluminescence. Anal. Chem. 2014, 86, 10535-10539.

(29) Broniowska, K. A.; Oleson, B. J.; McGraw, J.; Naatz, A.; Mathews, C. E.; Corbett, J. A. How the Location of Superoxide Generation Influences the beta-Cell Response to Nitric Oxide. J. Biol. Chem. 2015, 290, 7952-7960.

(30) Decad, G. M.; Nikaido, H. Outer Membrane of Gram-Negative Bacteria XII. Molecular-Sieving Function of Cell Wall. J. Bacteriol. 1976, 128, 325-336.

(31) Voelker, B. M.; Sedlak, D. L.; Zafiriou, O. C. Chemistry of Superoxide Radical in Seawater: Reactions with Organic $\mathrm{Cu}$ Complexes. Environ. Sci. Technol. 2000, 34, 1036-1042.

(32) El Badawy, A. M.; Luxton, T. P.; Silva, R. G.; Scheckel, K. G.; Suidan, M. T.; Tolaymat, T. M. Impact of Environmental Conditions (pH, Ionic Strength, and Electrolyte Type) on the Surface Charge and Aggregation of Silver Nanoparticles Suspensions. Environ. Sci. Technol. 2010, 44, 1260-1266.

(33) Yin, Y. G.; Shen, M. H.; Zhou, X. X.; Yu, S. J.; Chao, J. B.; Liu, J. F.; Jiang, G. B. Photoreduction and Stabilization Capability of Molecular Weight Fractionated Natural Organic Matter in Transformation of Silver Ion to Metallic Nanoparticle. Environ. Sci. Technol. 2014, 48, 9366-9373.

(34) Beyer, W. F.; Fridovich, I. Assaying for Superoxide-Dismutase Activity-Some Large Consequences of Minor Changes in Conditions. Anal. Biochem. 1987, 161, 559-566.

(35) Squadrito, G. L.; Pryor, W. A. Oxidative Chemistry of Nitric Oxide: The Roles of Superoxide, Peroxynitrite, and Carbon Dioxide. Free Radical Biol. Med. 1998, 25, 392-403.

(36) Mitzel, M. R.; Tufenkji, N. Transport of Industrial PVPStabilized Silver Nanoparticles in Saturated Quartz Sand Coated with Pseudomonas aeruginosa PAO1 Biofilm of Variable Age. Environ. Sci. Technol. 2014, 48, 2715-2723. 
(37) Abo, A.; Pick, E.; Hall, A.; Totty, N.; Teahan, C. G.; Segal, A. W. Activation of the NADPH Oxidase Involves the Small GTP-Binding Protein P21rac1. Nature 1991, 353, 668-670.

(38) Vignais, P. V. The Superoxide-Generating NADPH Oxidase: Structural Aspects and Activation Mechanism. Cell. Mol. Life Sci. 2002, 59, $1428-1459$.

(39) Spiro, T. G.; Bargar, J. R.; Sposito, G.; Tebo, B. M. Bacteriogenic Manganese Oxides. Acc. Chem. Res. 2010, 43, 2-9.

(40) Barber, M. J.; Kay, C. J. Superoxide Production during Reduction of Molecular Oxygen by Assimilatory Nitrate Reductase. Arch. Biochem. Biophys. 1996, 326, 227-232.

(41) O'Donnell, V. B.; Tew, D. G.; Jones, O. T. G.; England, P. J. Studies on the Inhibitory Mechanism of Iodonium Compounds with Special Reference to Neutrophil NADPH Oxidase. Biochem. J. 1993, 290, 41-49.

(42) Slade, S. J.; Pegg, G. F. The Effect of Silver and Other MetalIons on the in-Vitro Growth of Root-Rotting Phytophthora and Other Fungal Species. Ann. Appl. Biol. 1993, 122, 233-251.

(43) Ruoff, P.; Lillo, C. Molecular-Oxygen as Electron-Acceptor in the NADH-Nitrate Reductase System. Biochem. Biophys. Res. Commun. 1990, 172, 1000-1005.

(44) Yamasaki, H.; Sakihama, Y. Simultaneous Production of Nitric Oxide and Peroxynitrite by Plant Nitrate Reductase: In Vitro Evidence for the NR-Dependent Formation of Active Nitrogen Species. FEBS Lett. 2000, 468, 89-92.

(45) Kaiser, W. M.; Weiner, H.; Kandlbinder, A.; Tsai, C. B.; Rockel, P.; Sonoda, M.; Planchet, E. Modulation of Nitrate Reductase: Some New Insights, an Unusual Case and a Potentially Important Side Reaction. J. Exp. Bot. 2002, 53, 875-882.

(46) Klaus-Joerger, T.; Joerger, R.; Olsson, E.; Granqvist, C. G. Bacteria as Workers in the Living Factory: Metal-Accumulating Bacteria and Their Potential for Materials Science. Trends Biotechnol. 2001, 19, 15-20.

(47) Jha, A. K.; Prasad, K.; Prasad, K.; Kulkarni, A. R. Plant System: Nature's Nanofactory. Colloids Surf., B 2009, 73, 219-223.

(48) Marshall, J. A.; de Salas, M.; Oda, T.; Hallegraeff, G. Superoxide Production by Marine Microalgae. Mar. Biol. 2005, 147, 533-540.

(49) Minibayeva, F. V.; Gordon, L. K.; Kolesnikov, O. P.; Chasov, A. V. Role of Extracellular Peroxidase in the Superoxide Production by Wheat Root Cells. Protoplasma 2001, 217, 125-128.

(50) Xiu, Z. M.; Zhang, Q. B.; Puppala, H. L.; Colvin, V. L.; Alvarez, P. J. J. Negligible Particle-Specific Antibacterial Activity of Silver Nanoparticles. Nano Lett. 2012, 12, 4271-4275.

(51) Fujii, M.; Rose, A. L.; Waite, T. D.; Omura, T. Oxygen and Superoxide-Mediated Redox Kinetics of Iron Complexed by Humic Substances in Coastal Seawater. Environ. Sci. Technol. 2010, 44, 93379342.

(52) Abu-Saba, K. E.; Sedlak, D. L.; Flegal, A. R. Indirect Reduction of Hexavalent Chromium by Copper in the Presence of Superoxide. Mar. Chem. 2000, 69, 33-41.

(53) Zafiriou, O. C.; Voelker, B. M.; Sedlak, D. L. Chemistry of the Superoxide Radical in Seawater: Reactions with Inorganic Copper Complexes. J. Phys. Chem. A 1998, 102, 5693-5700.

(54) Hug, S. J.; Laubscher, H. U.; James, B. R. Iron(III) Catalyzed Photochemical Reduction of Chromium(VI) by Oxalate and Citrate in Aqueous Solutions. Environ. Sci. Technol. 1997, 31, 160-170.

(55) Gaberell, M.; Chin, Y. P.; Hug, S. J.; Sulzberger, B. Role of Dissolved Organic Matter Composition on the Photoreduction of $\mathrm{Cr}(\mathrm{VI})$ to $\mathrm{Cr}(\mathrm{III})$ in the Presence of Iron. Environ. Sci. Technol. 2003, 37, 4403-4409.

(56) Ferguson, M. A.; Hoffmann, M. R.; Hering, J. G. TiO ${ }_{2}^{-}$ Photocatalyzed As(III) Oxidation in Aqueous Suspensions: Reaction Kinetics and Effects of Adsorption. Environ. Sci. Technol. 2005, 39, 1880-1886.

(57) Lee, H.; Choi, W. Photocatalytic Oxidation of Arsenite in $\mathrm{TiO}_{2}$ Suspension: Kinetics and Mechanisms. Environ. Sci. Technol. 2002, 36, 3872-3878. 